\title{
Informal Production and Labour Market Segmentation
}

\author{
John Bennett*
}

26 February 2010

\begin{abstract}
An industry is modeled in which entrepreneurs, who are heterogeneous in ability, may produce formally or informally. Two cases are distinguished, with and without labour market segmentation, for which different patterns of formal/informal supply obtain. Without segmentation, informality may generate production where otherwise there would be none. Typically, however, a trade-off obtains: when informality makes output higher it cuts the profit of the most able entrepreneurs, potentially damaging growth. With segmentation, informality causes some replacement of 'good' jobs by 'bad', and total employment may be affected in either direction; without segmentation the effect on total employment is weakly positive. (JEL: O17, D2)
\end{abstract}

\section{Introduction}

The widespread existence of informality in developing economies is commonly viewed as having detrimental economic and social effects. ${ }^{1}$ This negative eval-

${ }^{*}$ Department of Economics and Finance, and Centre for Economic Development and Institututions (CEDI), Brunel University. I am grateful for very helpful comments by an anonymous referee. I would also like to thank Saul Estrin, Stephanie Levy and participants at The Third IZA/World Bank Conference on Employment and Development, Skhirat, Morocco, May, 2008, and at the UNU-WIDER Project Workshop on Entrepreneurship and Economic Development, Helsinki, August, 2008. Financial support from the Leverhulme Trust is gratefully acknowledged.

${ }^{1}$ Widely cited figures, taken from SCHNEIDER AND ENSTE [2000], put informal output in developing economies at about $40 \%$ of GDP, and informal employment at about $60 \%$ of total employment. A more recent figure given by SCHNEIDER [2006] is that the 'shadow economy' constitutes $38.7 \%$ of GDP, on average, for 96 developing economies. 
uation is partly the result of a focus on the labour market, which is seen as segmented, that is, with, at a given skill level, formal jobs being more attractive than informal jobs, but access to formal jobs being rationed (FIELDS [2009]). It is reinforced by evidence that informal firms are less efficient than formal ones (DE PAULA AND SCHEINKMAN [2008]). However, an alternative view, developed in the Latin American context, suggests that the labour market may not be segmented and that there may be dynamic benefits from informality. In particular, MALONEY [2004] argues that at least part of the informal sector involves voluntary employment and self-employment, and is the analogue of the entrepreneurial small-firm sector found in developed countries, where it is an engine of growth (see also BENNETT [2010]). Empirical evidence on whether there is informal/formal labour market segmentation is mixed, with conclusions differing significantly both across countries and across sectors within countries (see, e.g., BADAOUI ET AL. [2008]).

The present paper aims to further understanding of the impact of informality by formulating a model of the product market side, which has been little explored in the theoretical literature. We examine how the pattern of informality/formality in an industry depends on whether the labour market is segmented, as well as on the distribution of entrepreneurial abilities, the strength of product demand and parameters affecting the net costs and benefits of informality. We use this framework to examine various issues related to the welfare impact of informality. Throughout, we consider a production activity in which formality-versus-informality is an active choice for an entrepreneur. Our analysis is not meant to apply to the lower tier of informal activity, which has low value added, often only involving resale, with low capital-intensity and almost no paid employment. Rather, it relates to informal activity that can make profit, is more capital-intensive, involves paid employment and may entail competition with formal firms.

We assume that, unlike an informal firm, a formal firm must bear a registration cost. If the labour market is unsegmented, all firms pay the same money wage. If there is segmentation, however, formal firms additionally provide workers with social benefits (an alternative interpretation is that a formal firm pays a statutory minimum wage rate, while an informal firm pays a lower, market, wage rate). ${ }^{2}$ In the terminology of BOURGUIGNON [2005], when there is segmentation, formal jobs are 'good' and informal jobs 'bad.' We assume, however, that a formal firm obtains a productivity benefit from greater access to public services, including legal

\footnotetext{
${ }^{2}$ There is no generally agreed way to define informality, though lack of registration by the firm is included in most definitions. The two approaches commonly taken are also to specify that (a) the firm does not provide social security benefits; or (b) the firm does not exceed some employment size threshold. E.g., definition (a) has been used by the South African government and (b) by the Moroccan one (WALTHER AND FILIPIAK [2007]). We use (a) in this paper.
} 
protection and contract enforcement, that may be unavailable to an informal firm (STRAUB [2005]; AMARAL AND QUINTIN [2006]).

In practice, formality is also strongly associated with larger size: formal regulations may only apply to larger firms (see AHSAN AND PAGES [2007] on India) and, more generally, an entrepreneur operating informally may eschew expansion because of the risk of attracting the attention of the authorities (WORLD BANK [2007]). We reflect these considerations as simply as possible by assuming that for each entrepreneur only two levels of output are feasible. Fear of discovery and associated penalties are assumed sufficiently strong entirely to deter informality at the higher of these levels, and so informality occurs only at the lower one; but, because of increasing returns, if an entrepreneur chooses to operate formally, he or she chooses the higher level.

We differentiate entrepreneurs in terms of ability, through a multiplicative parameter on labour requirements. Given the formality-informality status chosen by an entrepreneur, greater entrepreneurial ability is associated with a lower total labour cost. ${ }^{3}$ To determine the effect of informality, we compare the industry equilibrium when each entrepreneur is free to choose either formality or informality (or to stay out), with one in which informality is ruled out.

If only formal production were possible the number of entrepreneurs that could produce profitably would be non-decreasing in price, and so the supply curve of output would be (weakly) positively sloped. When the option of operating informally is added into this picture, the choice between formality and informality for each entrepreneur must also be taken into account. At any potential price each entrepreneur weighs the productivity benefit and the potential profits that would come from the larger scale of formal production against the registration cost and, if there is segmentation, the higher unit labour cost that formality involves. Each entrepreneur views this comparison through the lens of his or her own ability, through its effect on total labour costs.

We develop the model first with labour market segmentation, and then without it. In each case we assume that parameter values are such that, depending on product demand, there may be a mix of formality and informality in equilibrium. This leads us to make different assumptions regarding the size of registration costs in the two cases. When there is segmentation, unit labour costs are greater for formality than informality for any given entrepreneur. For formality to be a viable option at least for some entrepreneurs at some level of demand, the net effect of some other factors must favour formality sufficiently. Thus, for segmentation, we

\footnotetext{
${ }^{3}$ The analysis is not affected substantively if capital costs, as well as, or instead of, labour costs are assumed to depend on an entrepreneur's ability. The idea behind our specific formulation is that a piece of equipment costs the same to an entrepreneur irrespective of his or her ability; but the cost of operating the equipment will be less for a more able entrepreneur.
} 
formulate our analysis in terms of the registration cost being less than a critical value, relative to the assumed productivity and scale advantages of formality. ${ }^{4}$ However, in the absence of segmentation, unit labour costs are the same for formality and informality, and so, since formal production has a productivity advantage and occurs at a greater scale, informality would never be chosen unless the registration cost were sufficiently large. For this case we assume that the registration cost exceeds the critical value mentioned above. ${ }^{5}$

Consider the segmentation case. When price is relatively low, the productivity and scale advantages of formality are correspondingly small. Since, by assumption, the registration cost is also small, entrepreneurs of a sufficiently high ability (for whom the absolute difference in total labour costs from producing formally rather than informally is relatively small) choose formality. Therefore, when product demand is relatively low, output is only formal, all coming from high-ability entrepreneurs. When product demand is higher, these entrepreneurs will, a fortiori, produce formally, but less able entrepreneurs also enter production. The more able of these additional entrants choose formality, but their production is supplemented by some informal entry by the less able. The latter entrepreneurs find informality the more profitable because, for them, the absolute difference in total labour costs from producing formally rather than informally is large. However, if product demand is so high that all available entrepreneurs have entered production, any further rises in demand are met by a switch of the less able entrepreneurs from informality to formality, to take advantage of the high product price through the scale and productivity benefits that formality involves. For a sufficiently high demand, all produce formally.

In the no-segmentation case, the registration cost is the only disadvantage of formality for an entrepreneur. However, at a relatively low price, the productivity and scale benefits of formality are relatively small, and so, with the registration cost sufficiently high, informality is preferred to formality, yielding a positive profit for the most able entrepreneurs. Hence, in contrast to the segmentation case, when product demand is relatively low, only informal production occurs. However, as product demand increases, informal production is steadily displaced by formal production. As price rises, the most able entrepreneurs, who at a low price operate informally, find that paying the registration cost and switching to formality is justified by the increased revenue that the associated greater scale of production

\footnotetext{
${ }^{4}$ We could alternatively have formulated the analysis in terms of the critical level of the productivity benefit, given any level of the registration cost.

${ }^{5}$ Two other potential cases are segmentation together with a high registration cost and no-segmentation with a low registration. We do not consider the former case separately because it turns out to be a special case, analytically, of the segmentation-low registration cost formulation. We disregard the latter case entirely because it would result in informality never being chosen.
} 
brings in. Again, when product demand is sufficiently high, all output is formal.

We go on to develop the model for a uniform distribution of entrepreneurial ability to obtain more detailed results. With and without segmentation, having the option of informality available to entrepreneurs can result in higher or lower total output (we specify the conditions). In particular, without segmentation there is a range of product demand for which some informal production occurs, whereas if informality were not possible there would be no production. Thus, informality can be welfare-enhancing. With the exception of this case, however, a trade-off is found: with or without segmentation, if having the option of informality causes output (and consumer surplus) to be greater, it is also found that the profits earned by the more able entrepreneurs are made smaller, and vice versa. If we suppose that investment by the more able entrepreneurs is important for the growth prospects of the industry, this implies that when informality is beneficial in terms of production it has a potentially adverse effect with regard to growth prospects.

With segmentation, the existence of informality as an option may affect the total number of jobs positively or negatively; but in either event, good jobs are destroyed - if the effect is positive it is because more bad jobs are created than good ones lost. Without segmentation, however, at low product demand, jobs are created where otherwise there would be none, while at higher product demand, jobs in informal firms displace jobs in formal firms on a one-for-one basis; that is, without segmentation, there is never a reduction in the total number of jobs.

Thus, our analysis suggests that, for given parameter values, there are potentially some positive aspects of informality, and so, given the widespread market imperfections in developing economies, (possibly tacit) support of informality may in some circumstances be seen as an appropriate second-best response. However, we end by considering comparative statics briefly, and, we show, in particular, that, with and without segmentation, a reduction in the registration cost is welfare enhancing (we disregard the use to which government income from registration costs may be put). Without segmentation, if the registration cost is reduced to zero there will be no informality; but when there is segmentation a zero registration cost may, depending on the level of demand, leave some informality in equilibrium.

In the theoretical literature on informality, heterogeneity of entrepreneurial ability was introduced by RAUCH [1991], using a variation of the LUCAS [1978] model in which ability is represented by a multiplicative parameter on output. He thereby explains why a 'missing middle' in the size distribution of firms may obtain. Our formulation shares with Rauch the assumption of a minimum wage rate (or, equivalently, social benefit provision) only in the formal sector, though we characterize entrepreneurial ability differently; and, at the cost of suppressing the endogenous choice of size for each firm that Rauch analyzes, we are able to examine in detail the product market and welfare ramifications. 
Various authors have analysed informality using the Lucas-Rauch formulation of entrepreneurial ability. These include FORTIN ET AL. [1997], who generate a gap in the size distribution of firms as a result of expenditure by informal firms on avoiding detection, and AMARAL AND QUINTIN [2006], who endogenize skills by developing an overlapping-generations model with occupational choice. Other building blocks of our model are also common in the literature, including higher wage rates paid by formal than by informal firms (e.g., GOLDBERG AND PAVCNIK [2003]) and the productivity benefit of formality (e.g., AMARAL AND QUINTIN [2006]). Factors that we do not include but which are also found in the literature include value-added taxation (DE PAULA AND SCHEINKMAN [2008]), differential cost of or access to outside finance (STRAUB [2005]; ANTUNES AND CAVALCANTI [2007]) and bribery (IHRIG AND MOE [2004]). A paper that, like ours, is concerned with the product market, is that of BANERJI AND JAIN [2007]. However, their focus is different, examining the endogenous differences in the quality of output between informal and formal firms.

There is also a literature that uses search-and-matching theory to analyse informality, based on the assumption that workers, rather than entrepreneurs, are heterogeneous in ability. For example, BOSCH [2007] assumes that workers are ex ante homogeneous, but, when brought together with firms, some matches are more productive than others, while ALBRECHT ET AL. [2009] develop a model in which ability-differences between workers affect their productivities if they are in formal jobs, but not if they are in informal ones. Because of the complexity of these models it is usually necessary to use simulations to obtain specific results. A recent contribution by ULYSSEA [2010], for example, uses Brazilian data and finds that lower entry costs to the formal sector are a particularly effective policy, resulting in greater formal employment and lower total unemployment.

In Section 2 the model is set up, while the next two sections examine the implications for the formal-informal mix - in Section 3 with labour market segmentation and in Section 4 without it. Section 5 gives further discussion of welfare-related aspects of informality. Section 6 concludes. Proofs are given in an appendix.

\section{The Model}

Consider a competitive industry, with free entry, producing a homogeneous good. A pool of entrepreneurs exists for this industry, each of whom may choose to run a firm with informal status, or with formal status, or to stay out of production. Running one firm requires an entrepreneur's full attention. A firm is a price-taker in the product and input markets. To allow for heterogeneity of entrepreneurial abilities, a cost coefficient $\lambda(>0)$ is attached to each entrepreneur, where $\lambda$ varies 
across entrepreneurs. A lower value of $\lambda$ reflects higher entrepreneurial ability (we refer to an entrepreneur with a given $\lambda$ as a ' $\lambda$-entrepreneur'). ${ }^{6} \mathrm{~A} \lambda$-entrepreneur faces a Leontief technology, with two scales of activity being possible. The larger scale involves twice as large an input package as the smaller does.

However, informality at the larger scale is ruled out because the combination of risk of discovery and potential penalties is too large to bear. If a $\lambda$-entrepreneur chooses informality, his or her firm operates at the smaller scale, earning profit

$$
\pi^{I}=p-w \lambda-k .
$$

$k$ units of capital are employed along with $\lambda$ units of labour to produce one unit of output. $p$ is the unit price of output; $w$ is the wage rate and the unit price of capital is set at unity.

Instead, an entrepreneur may choose formal status, for which there are several costs and benefits not found with informality. On the cost side, the entrepreneur must pay a registration cost $c$. Also, for each unit of labour employed, as well as the wage $w$, a firm with formal status must provide social benefits at the cost $s$ per worker. With $s>0$ the labour market is segmented, which we assume in Section 3 , while the unsegmented case $(s=0)$ is examined in Section 4 . On the benefit side, it is assumed that, per package of labour and capital inputs, a formal firm produces $\beta$ units of output, rather than the single unit produced by an informal firm. This may be because formal firms gain superior access to public goods such as public infrastructure, contract enforcement and property rights.

Given these assumptions, formality is associated with increasing returns to scale (the coefficient $\beta$ can be also interpreted as a purely technological returnsto-scale parameter) and so, if a $\lambda$-entrepreneur decides to produce formally, it will be at the larger scale, profit being given by

$$
\pi^{F}=2[\beta p-(w+s) \lambda-k]-c ; \quad \beta>1 .
$$

Note that the $\lambda$-coefficient applies to an entrepreneur regardless of whether formal or informal status is adopted.

We denote the opportunity cost for a $\lambda$-entrepreneur of running a firm (in the industry we analyse) by $\pi_{0}$, which, for simplicity, is assumed independent of $\lambda .{ }^{7}$ Using (1) and (2), we shall plot the loci for $\pi^{I}=\pi_{0}, \pi^{F}=\pi_{0}$ and $\pi^{F}=\pi^{I}$ in $(\lambda, p)$ space. We note here for reference the $(\lambda, p)$-combination, denoted by $\left(\lambda^{*}, p^{*}\right)$, at

\footnotetext{
${ }^{6}$ Thus, in contrast to LUCAS [1978] and RAUCH [1991], but similarly to JOVANOVIC [1982], we model differences in ability through a multiplicative parameter on costs (see PARKER [2004] for discussion of this issue).

${ }^{7} \mathrm{RAUCH}[1991]$ assumes that $\pi_{0}$ is the wage an entrepreneur could make as a worker. If we had assumed that $\pi_{0}$ is increasing in $\lambda$, i.e., that greater entrepreneurial ability in the industry we analyze implies a greater value in alternative uses, then the loci in Figure 1 would diminish in slope as $\lambda$ increases.
} 
which $\pi^{I}=\pi^{F}=\pi_{0}$, informality and formality each just breaking even:

$$
\begin{aligned}
\lambda^{*} & =\frac{\hat{c}-c}{2(s-\hat{s})} ; p^{*}=\frac{2 s k+(2 s+w) \pi_{0}-c w}{2(s-\hat{s})}, \text { where } \\
\hat{s} & =(\beta-1) w \\
\hat{c} & =2(\beta-1) k+(2 \beta-1) \pi_{0} .
\end{aligned}
$$

The role played by informality depends critically on whether $s \gtreqless \hat{s}$ and/or $c \gtreqless \hat{c}$. A necessary condition for informality possibly to be chosen by some entrepreneurs is that at least one of $c>\hat{c}$ and $s>\hat{s}$, i.e., at least one of the costs of formality is above the specified critical value. Given (4), if $s>\hat{s}$ then $s>0$, the labour market being segmented.

Note that $s \gtreqless \hat{s}$ is equivalent to $(w+s) \lambda / \beta \gtreqless w \lambda$, where, for a given $\lambda$, $(w+s) \lambda / \beta$ is the labour cost of a unit of output for formality and $w \lambda$ that for informality. In practice, a variety of factors influence which of these labour costs is the greater. Formal labour cost per unit of output will be relatively high if formal firms pay rents to workers. TEAL [1996] finds strong evidence of rent sharing with workers by formal manufacturing firms in Ghana, and he concludes that the $30 \%$ differential between formal and informal sectors conjectured by LEWIS [1954] for his seminal two-sector model is a substantial underestimate. Also, COLLIER AND GUNNING [1999] suggest that in some African countries governments may generate rents for formal firms on the implicit understanding that the firms will pay high wage rates to workers. Informal labour cost per unit of output may be relatively low if informal firms provide benefits that cost little but are greatly valued by workers. For example, informal firms may provide greater flexibility of hours, and family members may be employed without an explicit wage being paid (see WORLD BANK [2007] on such behaviour in Latin America). ${ }^{8}$

DJANKOV ET AL. [2002] find, across 85 countries at various levels of development, an average official registration cost of $47 \%$ of annual per capita GDP. If we take this figure as a stylized fact for our model, then, from (5), sufficient for $c<\hat{c}$, as we shall assume in Section 3, would be that $\pi_{0}$ exceed $47 \%$ of annual per capita GDP. However, Djankov et al. also find that the official registration cost is much higher in some countries, being above $100 \%$ of annual per capital GDP in 9 of their sample, the highest being $460 \%$ in the Dominican Republic. This suggests that a group of countries may exist with $c>\hat{c}$, as we assume in Section 4 .

\footnotetext{
${ }^{8}$ For simplicity, we do not allow for the costs of capital being different for informal than for formal firms. If capital is more expensive for informal firms because of lack of access to formal sources of finance, so that they use moneylenders, it becomes less likely that the appropriately amended version of (4) will be satisfied. However, informal firms may get the capital from family and friends. In Africa the interest rate for such loans is typically at or near zero. E.g., in Ghana, LA FERRARA [2003] finds a real interest rate of approximately zero within kin groups.
} 
Let $\lambda_{\min }$ and $\lambda_{\max }$ denote the respective lowest and highest values of $\lambda$ in the pool of entrepreneurs. If only minimal entrepreneurial skills are required in the industry this pool may be large relative to the number that would satisfy product demand at any price. Then the supply of entrepreneurs would never impose a binding constraint on total output and, with a great enough heterogeneity of abilities, $\lambda_{\max }$ may be so large that we can treat it as infinite. Alternatively, a binding finite upper bound on $\lambda$ may exist because the entrepreneurial skills the industry requires are relatively scarce. We focus on the latter case because a similar effect on the results will obtain even if the entrepreneurial skills are not scarce, but a complementary input is rationed.

\section{A Segmented Labour Market}

For this section we assume that $s>\hat{s}$ and $c<\hat{c}$. With $s>\hat{s}$, the labour market is segmented, while the inequality $c<\hat{c}$ is assumed to hold so that there may be a mix of formality and informality in equilibrium. It is found from (3) that, with these assumptions, $\lambda^{*}>0$ and $p^{*}>0$, the loci for $\pi^{I}=\pi_{0}, \pi^{F}=\pi_{0}$ and $\pi^{F}=\pi^{I}$ being as shown in Figure 1.9

\section{[Figure 1]}

The region in which formality is chosen is labelled F, with light shading; that in which informality is chosen is labelled I, with dark shading; that in which the entrepreneur stays out is labelled 0 , and is unshaded. For $(\lambda, p)$-combinations above (below) the $\pi^{F}=\pi^{I}$ locus, $\pi^{F}>(<) \pi^{I}$. Above (below) the $\pi^{I}=\pi_{0}$ locus, $\pi^{I}>(<) \pi_{0}$, and similarly for the $\pi^{F}=\pi_{0}$ locus. Hence, $\mathrm{F}$ is chosen for $(\lambda, p)$ above both the $\pi^{F}=\pi^{I}$ and $\pi^{F}=\pi_{0}$ loci. I is chosen for $(\lambda, p)$ below the $\pi^{F}=\pi^{I}$ locus but above the $\pi^{I}=\pi_{0}$ locus. For $(\lambda, p)$ below both the $\pi^{F}=\pi_{0}$ and $\pi^{I}=\pi_{0}$ loci an entrepreneur stays out of the industry.

We adopt the following notation for critical values of $\lambda$ :

$$
\begin{gathered}
\pi^{I}(\lambda)=\pi^{F}(\lambda) \text { when } \lambda(p)=\frac{(2 \beta-1) p-k-c}{w+2 s} \equiv \bar{\lambda}(p) ; \\
\pi^{I}(\lambda)=\pi_{0}(\lambda) \text { when } \lambda(p)=\frac{p-k-\pi_{0}}{w} \equiv \lambda^{I}(p) ; \\
\pi^{F}(\lambda)=\pi_{0}(\lambda) \text { when } \lambda(p)=\frac{\beta p-k-\left(c+\pi_{0}\right) / 2}{w+s} \equiv \lambda^{F}(p) .
\end{gathered}
$$

\footnotetext{
${ }^{9}$ If we were to assume that $c \geq \hat{c}$, as well as $s>\hat{s}$, the loci would not intersect within the positive quadrant. Then the relevant figure would be the same, in effect, as the part of Figure 1 to the right of $\lambda=\lambda^{*}$. Our analysis in this section therefore covers this possibility.
} 
We shall also refer to the inverse functions of (6)-(8). The $p$ at which, for a given $\lambda, \pi^{I}=\pi^{F}$, is written $\bar{p}(\lambda)$; the $p$ at which, for a given $\lambda, \pi^{I}=\pi_{0}$, is written $p^{I}(\lambda)$; and the $p$ at which, for a given $\lambda, \pi^{F}=\pi_{0}$, is written $p^{F}(\lambda)$.

By extending a horizontal line through any price $p$ in Figure 1 we can see the range of $\lambda$-values associated with informality, formality, or staying out of the industry for that level of $p$. Thus we can determine for each possible price $p$ the total supplies of output produced informally and formally.

We express total supply (and, later, demand) as per entrepreneur in the pool. The cumulative density of $\lambda$ is denoted by $G(\lambda)$, and the supply of output by informal and by formal firms, per entrepreneur, by $q_{s}^{I}(p)$ and $q_{s}^{F}(p)$, respectively, and total supply per entrepreneur is $q_{s}(p)=q_{s}^{I}(p)+q_{s}^{F}(p)$. For brevity, we shall henceforth omit the phrase 'per entrepreneur.' To keep the language simple the results will be stated for a continuous $\lambda$-distribution. The following proposition characterizes the formal, informal and total supply curves.

Proposition 1 Informal and formal supply in a segmented labour market. Assume $s>\hat{s}, c<\hat{c}$ and $\lambda^{*} \in\left[\lambda_{\min }, \lambda_{\max }\right]$. Then (a) for $p \in\left[0, p^{F}\left(\lambda_{\min }\right)\right)$ supply is zero; (b) for $p \in\left[p^{F}\left(\lambda_{\min }\right), p^{*}\right]$ supply is only formal and is increasing in $p$; (c) for $p \in\left(p^{*}, \bar{p}\left(\lambda_{\max }\right)\right]$ supply is a mix of formality and informality and is increasing in $p$; (d) for $p \in\left(\bar{p}\left(\lambda_{\max }\right), \infty\right)$ supply is all formal and is constant.

Thus, above the minimum price $p=p^{F}\left(\lambda_{\min }\right)$ that induces entry, three $p$-ranges can be distinguished: a 'low' $p$ (range (b)) is associated with formality only; an 'intermediate' $p$ (range (c)) is associated with a formal-informal mix; and a 'high' $p$ (range $(\mathrm{d})$ ) is associated with formality only. We now turn to the intuition.

In the low $p$-range (b), entry is profitable for an entrepreneur with sufficiently low $\lambda$. The impact of a low $\lambda$ on total labour costs is greater for formality, which uses more labour at a higher unit cost, than for informality, and is reinforced by the productivity benefit $\beta$ and the larger size (and so, potentially, ability to make profit) of formality. Thus, only formal production occurs, with only the relatively able entrepreneurs producing. Given that $c<\hat{c}$, the registration $\operatorname{cost} c$ of formality is not so great as to prevent this outcome.

In the intermediate $p$-range (c), production also becomes profitable for entrepreneurs who do not have such a low $\lambda$. Of those producing when $p$ is in this range, those with a lower $\lambda$ choose formality for the reason outlined above. But those with a higher $\lambda$ prefer informality because a higher $\lambda$ magnifies total labour costs and so has a greater negative impact on the profit that would obtain from formal than from informal status. This outweighs the benefits that would accrue from formality - from greater scale and from $\beta$. Thus there is a mix of formality and informality, and as $p$ rises within range (c), entrepreneurs with a relatively high $\lambda$ become able to obtain a profit from entering production informally. At the 
same time, as $p$ rises entrepreneurs near the margin of choice between formality and informality steadily switch from informality to formality because the $p$ rise increases the benefits from greater scale and from $\beta$.

In the high $p$-range (d) all entrepreneurs have entered production and the switch from informality to formality is complete. If $p$ is raised above $\bar{p}\left(\lambda_{\max }\right)$ there is no effect on output: all entrepreneurs are already producing formally.

To derive specific supply curves we assume that the distribution of $\lambda$ is uniform, with mean $\Lambda$ and upper and lower bounds $\Lambda \pm \delta(\Lambda>\delta>0)$, where $\Lambda-\delta<\lambda^{*}<$ $\Lambda+\delta$. Thus, $\Lambda-\delta=\lambda_{\min }$ and $\Lambda+\delta=\lambda_{\max }$ and the cumulative density function is $G(\lambda)=(\lambda-\Lambda+\delta) / 2 \delta$ for $\lambda \in[\Lambda-\delta, \Lambda+\delta]$. The following corollary summarizes the impact that the existence of the option of informality has on total supply.

Corollary 1 With $s>\hat{s}$ and $c<\hat{c}$, suppose $\lambda \sim U[\Lambda-\delta, \Lambda+\delta]$. The effect that the option of informality has on total supply is positive for $p \in\left(p^{*}, \tilde{p}\right)$, but negative for $p \in\left(\hat{p}, \bar{p}\left(\lambda_{\max }\right)\right)$, where $p=\tilde{p}$ solves $(2 \beta-1) G[\bar{\lambda}(p)]+1=2 \beta G\left[\lambda^{F}(p)\right]$. For $p$ outside these ranges it has no effect on total supply.

The effect that the option of informality has on total output depends on the interaction of this supply effect with demand. In Figure $2, \bar{q}_{s}^{F}(p)$, as shown by the thick line TVR, denotes what supply would be if informality were ruled out. This is upward sloping until point $\mathrm{V}\left(p=p^{F}\left(\lambda_{\max }\right)\right)$, where all of the pool of entrepreneurs are operating formally, supply then being vertical. However, if informality is an option, it is exercised by some entrepreneurs when the demand curve cuts $\bar{q}_{s}^{F}(p)$ between $\mathrm{Z}$ and Y. Then, formal supply $q_{s}^{F}(p)$ is shown by ZY, aggregate supply $q_{s}^{F}(p)+q_{s}^{I}(p)$ is TZWYR, and informal supply $q_{s}^{I}(p)$ is the horizontal difference between the two. The vertical distance between $\mathrm{Z}$ and $\mathrm{Y}$ is $p$-range (c) in Proposition 1.

[Figure 2]

Since Corollary 1 and Figure 2 are a special case of Proposition 1, the explanation already given still applies. However, the uniform distribution has its own properties. We know from Proposition 1 that as $p$ rises from $p^{*}$ some entrepreneurs switch from informality to formality (with a negative effect on informal supply) and some others switch from inactivity to informality (with a positive effect on informal supply). Thus, there are conflicting effects on informal supply, but we were not able to tell, for the general case, which effect was the greater. However, with a uniform distribution the positive effect dominates (the horizontal gap between $q_{s}^{F}(p)$ and $q_{s}^{F}(p)+q_{s}^{I}(p)$ increases as we move up from $\mathrm{Z}$ to $\left.\mathrm{W}\right)$ and so informal, as well as formal, supply is increasing in $p$. When $p$ is raised from $p^{I}\left(\lambda_{\max }\right)$ there are no additional entrepreneurs available to produce informally and so $q_{s}^{I}(p)$ declines, 
but because of the switch to formality explained above, $q_{s}^{F}(p)$ rises by more than $q_{s}^{I}(p)$ declines. Informal supply decreases between $\mathrm{W}$ and $\mathrm{Y}$, where all supply is formal.

Combining this characterization of the supply side with a demand curve for output, we have that, in Figure 2, the impact of having informality as an option is that if the demand curve intersects $\bar{q}_{s}^{F}(p)$ between $\mathrm{Z}$ and $\mathrm{X}$, output is made greater, while if it intersects between $\mathrm{X}$ and $\mathrm{Y}$ output is made smaller.

\section{An Unsegmented Labour Market}

We now examine how the analysis is affected if $s=0$, so that the labour market is not segmented. We interpret this as formal firms paying no social benefits. It may instead be interpreted as the absence of a binding minimum wage for formal employment or, equivalently, it may be supposed that both types of firms pay social benefits so as to compete in the labour market (see WORLD BANK [2007]) with, algebraically, social benefits incorporated into $w$. There are now no good jobs or bad jobs: all jobs are identical. For there possibly to be any informality, it is necessary that $c>\hat{c}$, which we now assume. Since the results for $s=0$ are the same, qualitatively, as for any $s \in[0, \hat{s})$, our results also cover the case of a 'small' amount of segmentation. The profit loci are shown in Figure 3 (note that the values of $p^{*}$ and $\lambda^{*}$ are different to in the segmentation case). The choices made by entrepreneurs are labelled and shaded as in Figure 1.

[Figure 3]

Parallel to Proposition 1 we obtain the following.

Proposition 2 Informal and formal supply in an unsegmented labour market. Assume $s=0, c>\hat{c}$ and $\lambda^{*} \in\left[\lambda_{\min }, \lambda_{\max }\right]$. Then (a) for $p \in\left[0, p^{I}\left(\lambda_{\min }\right)\right)$ supply is zero; (b) for $p \in\left[p^{I}\left(\lambda_{\min }\right), \bar{p}\left(\lambda_{\min }\right)\right]$ supply is only informal and is increasing in $p$; (c) for $p \in\left(\bar{p}\left(\lambda_{\min }\right), p^{*}\right]$ supply is a mix of formality and informality; formal and total supply are increasing in p but informal supply is decreasing in $p$; (d) for $p \in\left(p^{*}, \infty\right)$ supply is all formal, increasing in $p$ up to $p=p^{F}\left(\lambda_{\max }\right)$, and then constant.

Thus, above the minimum price $p=p^{I}\left(\lambda_{\text {min }}\right)$ that induces entry, three $p$-ranges can be distinguished: a 'low' $p$ (range (b)) is associated with informality only; an 'intermediate' $p$ (range (c)) is associated with a formal-informal mix; and a 'high' $p$ (range $(\mathrm{d}))$ is associated with formality only. We now turn to the intuition.

As in the segmented case, at a low $p$ entry is only profitable for low- $\lambda$ entrepreneurs; but in the present case they enter informally, whereas with segmentation 
they entered formally. This difference between Propositions 1 and 2 stems from the differing assumptions regarding both $s$ and $c$. Because of the role of the productivity parameter $\beta$, when $s=0$ the labour cost of producing a unit of output is less for formality than for informality, and the scale effect of formality magnifies the associated profit. Nonetheless, when $p$ is sufficiently low (range (b)), so that the scale and productivity benefits of formality are small, the large registration cost makes formality unprofitable - although entrepreneurs with a sufficiently low $\lambda$ can nonetheless make a profit from informality.

When $p$ is higher, in the intermediate range (c), the scale and productivity benefits of formality are magnified. Even with the high registration cost, entrepreneurs with sufficiently low $\lambda$ find formality profitable, and more so than informality. At the same time, those with a somewhat higher $\lambda$, i.e., higher labour costs, cannot profit from formality, but they can make a profit from informality because it has no registration cost. Thus, the move from a low $p$ to an intermediate one causes the more able entrepreneurs to switch from informality to formality, as well as making informality profitable for the somewhat less able. There is a mix of formality and informality.

In the high $p$-range (d) the switch is complete: all those who would have produced informally at a $p$ in range (b) or (c) now choose formality. When $p$ is higher within this range, the scale and productivity advantages of formality are yet greater, and so more entrepreneurs enter, all choosing formality, until all entrepreneurs are producing.

Corresponding to Corollary 1, we have the following:

Corollary 2 With $s=0$ and $c>\hat{c}$, suppose $\lambda \sim U[\Lambda-\delta, \Lambda+\delta]$. The option of informality has a positive impact on supply if $p \in\left(p^{I}\left(\lambda_{\min }\right), p_{x}\right)$, but a negative one if $p \in\left(p_{x}, p^{*}\right)$, where $p=p_{x} \in\left(p^{F}\left(\lambda_{\min }\right), \bar{p}\left(\lambda_{\min }\right)\right]$. For $p$ outside these ranges it has no effect on output.

This is illustrated in Figure 4, with $\bar{q}_{s}^{F}(p)$ (shown by VTS) again denoting what supply would be in the absence of informality. The shape of the supply curve $q_{s}^{F}(p)+q_{s}^{I}(p)$ (YXWTS) reflects Proposition 2 - the only additional feature that the uniform-distribution example brings to the picture is linearity.

\section{[Figure 4]}

\section{Further Discussion}

Although expressions for the impact of the option of informality on total welfare, both with and without segmentation, are intractable, we can gain insights into the effects on some aspects of welfare. We assume a uniform distribution of $\lambda$, 
as specified above, and that the demand curve is downward-sloping and is located such that, in Figure 2 or 4 , as appropriate, there is some informality in equilibrium. Thus, denoting by $\bar{p}^{F}$ the price at which demand cuts $\bar{q}^{F}(p)$, in Figure 2 demand passes above $\mathrm{Z}$ and below $\mathrm{Y}$, i.e., $\bar{p}^{F} \in\left(p^{*}, \bar{p}\left(\lambda_{\max }\right)\right)$; in Figure 4 demand passes above $\mathrm{Y}$ and below $\mathrm{W}$, i.e., $\bar{p}^{F} \in\left(p^{I}\left(\lambda_{\min }\right), p^{*}\right)$.

The impact on consumer surplus $(C S)$ of informality being an option follows from our previous results. When there is a positive (negative) impact on total output, price falls (rises) and there is a positive (negative) impact on $C S$. Although we cannot generally determine the impact of informality on aggregate profits, we are able to examine the impact on the profits of relatively able entrepreneurs (e.g., for $\left.\lambda=\lambda_{\min }\right)$. This may be important because the profits of these entrepreneurs may have a significant effect on the quantity and quality of investment, and thus on growth prospects. There is one case in which informality is unconditionally beneficial: without segmentation, if $\bar{p}^{F} \in\left(p^{I}\left(\lambda_{\min }\right), p^{F}\left(\lambda_{\min }\right)\right]$ we have both that $C S$ is raised (there is no production without informality) and the profit generated goes to the more able entrepreneurs. However, for segmentation and for some price ranges without segmentation a trade-off obtains: when having the option of informality increases $C S$, it reduces the profit of the more able entrepreneurs, and vice versa.

Lemma 1 An intertemporal trade-off from informality. If $\lambda \sim U[\Lambda-\delta, \Lambda+$ $\delta]$ and the demand curve is downward sloping with, in equilibrium, some informality, having the option of informality has the following effects. (i) With segmentation, if $\bar{p}^{F} \in\left(p^{*}, \tilde{p}\right), C S$ rises, but more able entrepreneurs get less profit; if $\bar{p}^{F} \in\left(\tilde{p}, \bar{p}\left(\lambda_{\max }\right)\right)$, the reverse effects hold. (ii) Without segmentation, if $\bar{p}^{F} \in\left(p^{F}\left(\lambda_{\min }\right), p_{x}\right), C S$ rises, but more able entrepreneurs get less profit; if $\bar{p}^{F} \in\left(\bar{p}\left(\lambda_{\min }\right), p^{*}\right)$, the reverse effects hold.

In Figure 2 (with segmentation) if $\bar{p}^{F} \in\left(p^{*}, \bar{p}\left(\lambda_{\max }\right)\right)$, low- $\lambda$ entrepreneurs produce formally regardless of whether informality is an option. However, when informality is an option, the impact on total output is positive if $\bar{p}^{F} \in\left(p^{*}, \tilde{p}\right)$, so that $p$ is lower and $C S$ higher, taking some profit away from the low- $\lambda$ entrepreneurs; while if $\bar{p}^{F} \in\left(\tilde{p}, \bar{p}\left(\lambda_{\max }\right)\right)$ the opposite results obtain. Without segmentation a similar argument applies. In Figure 4 , if $\bar{p}^{F} \in\left(p^{F}\left(\lambda_{\min }\right), p_{x}\right)$ low- $\lambda$ entrepreneurs produce informally when it is an option, but formally otherwise, with, in the former case, total supply being greater and so $p$ lower. Therefore the low- $\lambda$ entrepreneurs get less profit when informality is an option, but $C S$ is then higher. If $\bar{p}^{F} \in\left(\bar{p}\left(\lambda_{\min }\right), p^{*}\right)$ low- $\lambda$ entrepreneurs produce formally irrespective of whether informality can be chosen; but when informality can be chosen total output is lower and $p$ is higher, so these entrepreneurs earn higher profits, whereas $C S$ is 
lower. ${ }^{10}$

When informality is an option for entrepreneurs, the number and type of jobs may also be affected. With segmentation, if there is any informality in equilibrium, the impact on the number of good jobs is negative, but the total number of jobs may be affected in either direction, the effect being positive for a relatively low $p$ and negative for a relatively high one. Without segmentation, the effect of informality being an option is that the number of jobs increases at a relatively low price, but is unaffected at a relatively high one.

Proposition 3 The total employment effect of informality. Suppose $\lambda \sim U[\Lambda-$ $\delta, \Lambda+\delta]$ and that there is some informality in equilibrium. (i) With segmentation, having the option of informality raises the total number of jobs if $\bar{p}^{F} \in\left(p^{*}, \tilde{p}^{l}\right)$ but reduces it if $\bar{p}^{F} \in\left(\tilde{p}^{l}, \bar{p}\left(\lambda_{\max }\right)\right)$, where $\tilde{p}^{l} \in\left(p^{I}\left(\lambda_{\max }\right), p^{F}\left(\lambda_{\max }\right)\right]$. (ii) Without segmentation it raises the total number of jobs if $p \in\left(p^{I}\left(\lambda_{\min }\right), \bar{p}\left(\lambda_{\min }\right)\right)$ but has no effect on the total number of jobs if $p \in\left[\bar{p}\left(\lambda_{\min }\right), p^{*}\right)$.

With segmentation, we have seen that the option of informality may affect output in either direction. In Figure 2, the output effect is positive if the demand curve passes between $\mathrm{Z}$ and $\mathrm{X}$, but negative if it passes between X and Y. Proposition 3(i) is the analogue of this result for total employment. Because, for any $\lambda$, labour productivity is lower for informality than formality, it follows that if $q_{s}^{F}(p)+q_{s}^{I}(p) \geq \bar{q}_{s}^{F}(p)$ (i.e., up to $p=\tilde{p}$ in Figure 2) then $l_{s}^{F}(p)+l_{s}^{I}(p)>\bar{l}_{s}^{F}(p)$. Therefore, the critical price, $p=\tilde{p}^{l}$ in Proposition 3 , at which $l_{s}^{F}(p)+l_{s}^{I}(p)=\vec{l}_{s}^{F}(p)$, exceeds $\tilde{p}$. Without segmentation, a similar argument obtains, with the critical value of $p$ being $\bar{p}\left(\lambda_{\min }\right)$, but, for $p$ above this value the total number of jobs is the same with and without the option of informality.

The results above are obtained for given parameter values, but the parameters $s$ and $c$ may be varied directly by government policy, with results as follows. ${ }^{11}$

Lemma 2 Reduced costs of formality. If $\lambda \sim U[\Lambda-\delta, \Lambda+\delta]$ a smaller registration cost $c$ or social benefit cost $s$ is (weakly) associated with greater total output and employment both with and without labour market segmentation.

A lower level of $c$ or $s$ favours formality at the expense of informality, as would be expected; but, as stated in Lemma 2, with a uniform distribution of ability,

\footnotetext{
${ }^{10}$ There is also one case in which $C S$ is affected by informality, but the effect on the profits of the most able is unclear. That is when there is no segmentation and $\bar{p}^{F} \in\left(p_{x}, \bar{p}\left(\lambda_{\min }\right)\right)$.

${ }^{11}$ The lemma is obtained by differentiating the expressions for total output and employment in the proofs to Corollaries 1-2. Similarly, with and without segmentation, lower values of $s, w, k$ and $\pi_{0}$ and a higher $\beta$ are weakly associated with greater total output and employment.
} 
the positive effects on formal output and employment dominate, regardless of whether there is segmentation. (Also, the profits of the most able entrepreneurs rise.) Indeed, if we assume that government revenue from registration costs is not used to enhance welfare, then, as also found by ULYSSEA [2010] in a searchand-matching model of informality, a lower level of $c$ is (weakly) associated with greater welfare. (The same conclusion would only follow for a lower $s$ if the lower cost of providing social benefits were not associated with a reduction in the utility of social benefits.) An implication of this argument is that $c$ should be reduced to zero. The effects differ, however, depending on whether there is segmentation. With segmentation, even if $c=0$ our analysis in Section 3 still applies. Without segmentation, when $c \leq \hat{c}$ informality disappears altogether.

Finally, the model is relevant to the debate on the cyclicality of informality. In dual labour market (segmentation) models (on which, see FIELDS [2009]) informal employment and output expand during recessions because formal employment, which is rationed, falls, while the informal labour market clears. However, recent research on Latin America suggests that on some measures informality may be pro-cyclical (see, e.g., BOSCH AND MALONEY [2008]), and our analysis is consistent with this view. In both Figure 2 and Figure 4 there are stretches of $q_{s}^{F}(p)+q_{s}^{I}(p)$ that are steeper than $\bar{q}_{s}^{F}(p)$ and stretches that are flatter, at a given price. In either figure, a small vertical deviation in demand can, depending on the initial level of demand, cause a smaller or a larger change in output in the presence of informality than without it. In this sense informality can be a built-in stabilizer or destabilizer.

\section{Conclusion}

Most of the theoretical literature on informality has focused on the labour market. In this paper we analyse the impact of informality by focusing on the production side, though the labour market still plays a key role. A simple stylized framework is developed for analyzing the mix of formality and informality in an industry with entrepreneurs of heterogeneous ability. The results are classified according to whether the labour market is segmented or not, with, in each case assumptions made on parameter values such that a formal-informal mix obtains at some level of demand.

We find that, both with and without segmentation, the existence of the option of informality can affect output in either direction. In each case, supply is all formal at a high enough price, and there is a mix of formality and informality at an intermediate price. However, when price is sufficiently low in the segmentation case all supply is formal, whereas at a sufficiently low price in the absence of segmentation all supply is informal. These conclusions depend on there be- 
ing a sufficiently wide range of entrepreneurial abilities. There is one scenario in which having the option of informality results in production when there would otherwise be one; that is in the case of an unsegmented labour market when demand is relatively low. However, in other circumstances, when the effect on total output (and consumer surplus) is positive, the impact on the profits of the most able entrepreneurs is negative, and vice versa. We suggest that this implies an intertemporal trade-off, for the profits of the most able entrepreneurs may be particularly important for investment and growth. Without segmentation, the effect on total employment of having the option of informality is weakly positive. With segmentation this effect may go in either direction, but when informality occurs it involves some replacement of some good jobs with bad. Consistent with recent empirical evidence which suggests that in unsegmented labour markets informality may be destabilizing in some respects, we find that informality may be stabilizing or destabilizing, and this conclusion also applies to segmented labour markets.

These results are all obtained for given parameter values. We also consider comparative statics briefly. In particular, we find that a reduction of the registration cost raises welfare. If, for example, this cost is reduced to zero, then, without segmentation there would be no informality. If, however, segmentation is viewed as a given, informality may not be not eliminated by a zero registration cost (depending on the level of demand). Then, informality may be regarded in a second-best light: as we have seen, it has costs and benefits and, depending on the welfare weights assigned to these outcomes, as well as on parameter values and the level of demand, it may be welfare-enhancing.

In further research, the sensitivity of our results to the distribution of entrepreneurial abilities and to alternative definitions of informality might be considered. Instead of assuming that only two sizes of firm are possible for any given entrepreneur, size choice could be endogenizied, in essence combining our approach with that of RAUCH [1991]. Also, penalties for being caught operating informally could be introduced into the model: depending on these, and on the probability of discovery, entrepreneurs might risk expanding informal firms.

\section{Appendix: Proofs}

\section{Proposition 1}

Raising $p$ from zero, (formal) entry first occurs at $p=p^{F}\left(\lambda_{\min }\right)$. (b) For $p \in\left[p^{F}\left(\lambda_{\min }\right), p^{*}\right]$, there is formality for all $\lambda \leq \lambda^{F}(p)$, i.e., $q_{s}^{F}(p)=2 \beta G\left[\lambda^{F}(p)\right]$, so that $q_{s}^{F^{\prime}}(p)>0$; but $q_{s}^{I}(p)=0$. (c) For $p \in\left(p^{*}, \bar{p}\left(\lambda_{\max }\right)\right]$, formality occurs for all $\lambda \leq \bar{\lambda}(p)$, i.e., $q_{s}^{F}(p)=2 \beta G[\bar{\lambda}(p)]$. (c) splits into two with respect to informality: for $p \in\left(p^{*}, p^{I}\left(\lambda_{\max }\right)\right]$ informality occurs for all $\lambda \in\left(\bar{\lambda}(p), \lambda^{I}(p)\right]$, i.e., $q_{s}^{I}(p)=G\left[\lambda^{I}(p)\right]-G[\bar{\lambda}(p)]$, so that $q_{s}^{F}(p)+q_{s}^{I}(p)=(2 \beta-1) G[\bar{\lambda}(p)]+G\left[\lambda^{I}(p)\right]$, and $q_{s}^{F \prime}(p)+q_{s}^{I \prime}(p)>0$; for $p \in\left(p^{I}\left(\lambda_{\max }\right), \bar{p}\left(\lambda_{\max }\right)\right]$ informality occurs for all $\lambda \in\left(\bar{\lambda}(p), \lambda_{\max }\right]$, i.e., $q_{s}^{I}(p)=G\left[\lambda_{\max }\right]-G[\bar{\lambda}(p)]$, so that $q_{s}^{F}(p)+q_{s}^{I}(p)=(2 \beta-$ 
1) $G[\bar{\lambda}(p)]+G\left[\lambda_{\max }\right]$, and $q_{s}^{F^{\prime}}(p)+q_{s}^{I \prime}(p)>0$. (d) For $p \in\left[\bar{p}\left(\lambda_{\max }\right), \infty\right)$ there is formality for all $\lambda$ : $q_{s}^{F}(p)=2 \beta$. Q.E.D.

\section{Corollary 1}

For $p \in\left(p^{F}\left(\lambda_{\min }\right), p^{F}\left(\lambda_{\max }\right)\right], \bar{q}_{s}^{F}(p)=2 \beta G\left[\lambda^{F}(p)\right] ; \operatorname{using}(8), d p / d \bar{q}_{s}^{F}(p)=$ $\delta(w+2 s) / \beta(2 \beta-1)$. For $p \in\left(p^{*}, \bar{p}\left(\lambda_{\max }\right)\right], q_{s}^{F}(p)=2 \beta G[\bar{\lambda}(p)]$; using $(6), d p / d q_{s}^{F}(p)=$ $\delta(w+s) / \beta^{2}$.

(a) $p \in\left[0, p^{F}\left(\lambda_{\min }\right)\right]: q_{s}^{I}(p)=q_{s}^{F}(p)=\bar{q}_{s}^{F}(p)=0$.

(b) $p \in\left(p^{F}\left(\lambda_{\min }\right), p^{*}\right]: q_{s}^{F}(p)=2 \beta G\left[\lambda^{F}(p)\right]=\bar{q}_{s}^{F}(p)$. Thus, using (4), $d p / d \bar{q}_{s}^{F}(p)<$ $d p / d q_{s}^{F}(p)$.

(c) $p \in\left(p^{*}, \bar{p}\left(\lambda_{\max }\right)\right]:$ for $p \in\left(p^{*}, p^{I}\left(\lambda_{\max }\right)\right], q_{s}^{I}(p)=G\left[\lambda^{I}(p)\right]-G[\bar{\lambda}(p)]$. Using (6)-(7),

$q_{s}^{F}(p)+q_{s}^{I}(p)-\bar{q}_{s}^{F}(p)=\left[2 \beta\left(\frac{(2 \beta-1) p-k-c}{w+2 s}-\frac{\beta p-k-\left(c+\pi_{0}\right) / 2}{w+s}\right)+\frac{p-k-\pi_{0}}{w}\right] / 2 \delta \equiv x / 2 \delta ;$ using (4), $d x / d p=\{2 s[s-\hat{s}] / w+s+w+2 w \beta(\beta-1)\} /(2 s+w)(s+w)>$ 0 . Substituting $p=p^{*}$ into $q_{s}^{F}(p)+q_{s}^{I}(p)-\bar{q}_{s}^{F}(p)=x / 2 \delta$ and using (5) and (4), $q_{s}^{F}\left(p^{*}\right)+q_{s}^{I}\left(p^{*}\right)-\bar{q}_{s}^{F}\left(p^{*}\right)>0$. Hence, $q_{s}^{F}(p)+q_{s}^{I}(p)-\bar{q}_{s}^{F}(p)>0$. For $p \in\left(p^{I}\left(\lambda_{\max }\right), \bar{p}\left(\lambda_{\max }\right)\right], q_{s}^{I}(p)=1-G[\bar{\lambda}(p)] . \quad \mathrm{Using}(6), d p / d\left[q_{s}^{F}(p)+q_{s}^{I}(p)\right]=$ $2 \delta(w+s) /(2 \beta-1)^{2}$. Using $(4), d p / d\left[q_{s}^{F}(p)+q_{s}^{I}(p)>d p / d \bar{q}_{s}^{F}(p)\right.$. At X in Figure $2, \bar{q}_{s}^{F}(p)=2 \beta G\left[\lambda^{F}(p)\right]$ equals $q_{s}^{F}(p)+q_{s}^{I}(p)=2 \beta G[\bar{\lambda}(p)]+1-G[\bar{\lambda}(p)]$. Thus, for $p=\tilde{p}, 2 \beta G\left[\lambda^{F}(\tilde{p})\right]=(2 \beta-1)[\bar{\lambda}(\tilde{p})]+1$.

(d) $p \in\left(\bar{p}\left(\lambda_{\max }\right), \infty\right): q_{s}^{I}(p)=0$ and $q_{s}^{F}(p)=\bar{q}_{s}^{F}(p)$; so $q_{s}^{I}(p)+q_{s}^{F}(p)=\bar{q}_{s}^{F}(p)$. Q.E.D.

\section{Proposition 2}

Let $s=0$ and $c>\hat{c}$. Using (1)-(2), we obtain the profit loci in Figure 3. (a) For $p \in\left[0, p^{I}\left(\lambda_{\min }\right)\right], q_{s}^{I}(p)=q_{s}^{F}(p)=0$. (b) For $p \in\left(p^{I}\left(\lambda_{\min }\right), \bar{p}\left(\lambda_{\min }\right)\right]$, there is informality $\lambda \leq \lambda^{I}(p)$, i.e., $q_{s}^{I}(p)=G\left[\lambda^{I}(p)\right]$, which is increasing in $p$; but $q_{s}^{F}(p)=0$. (c) For $p \in\left(\bar{p}\left(\lambda_{\min }\right), p^{*}\right], q_{s}^{I}(p)=G\left[\lambda^{I}(p)\right]-G[\bar{\lambda}(p)]$ and $q_{s}^{F}(p)=$ $2 \beta G[\bar{\lambda}(p)]$; hence, $q_{s}^{F \prime}(p)>0$ and, using (6) and (7) with $s=0, q_{s}^{I \prime}(p)<0$; but $q_{s}^{I}(p)+q_{s}^{F}(p)=(2 \beta-1) G[\bar{\lambda}(p)]+G\left[\lambda^{I}(p)\right]$, which is increasing in $p$. (d) For $p \in\left(p^{*}, p^{F}\left(\lambda_{\max }\right)\right], q_{s}^{F}(p)=2 \beta G[\bar{\lambda}(p)]$, which is increasing in $p$, but $q_{s}^{I}(p)=0$; for $p \in\left(p^{F}\left(\lambda_{\max }\right), \infty\right), q_{s}^{F}(p)=2 \beta$ and $q_{s}^{I}(p)=0$. Q.E.D.

\section{Corollary 2}

(a) $p \in\left[0, p^{I}\left(\lambda_{\min }\right)\right]: q_{s}^{I}(p)=q_{s}^{F}(p)=\bar{q}_{s}^{F}(p)=0$.

(b) $p \in\left(p^{I}\left(\lambda_{\text {min }}\right), \bar{p}\left(\lambda_{\text {min }}\right)\right]: q_{s}^{F}(p)=0 ; q_{s}^{I}(p)=\left[\lambda^{I}(p)-\Lambda+\delta\right] / 2 \delta=[(p-k-$ $\left.\left.\pi_{0}\right) / w-\Lambda+\delta\right] / 2 \delta$, so that $d p / q_{s}^{I}(p)=d p / d q_{s}^{I}(p)=2 \delta w$. For $p \in\left[p^{I}\left(\lambda_{\min }\right), p^{F}\left(\lambda_{\min }\right)\right]$, $\bar{q}_{s}^{F}(p)=0$; for $p \in\left(p^{F}\left(\lambda_{\min }\right), \bar{p}\left(\lambda_{\min }\right)\right], \bar{q}_{s}^{F}(p)=2 \beta G\left[\lambda^{F}(p)\right]=\beta\left[\lambda^{F}(p)-\Lambda+\delta\right] / \delta=$ $\beta\left\{\left(2 \beta p-2 k-c-\pi_{0}\right) / 2 w-\Lambda+\delta\right\} / \delta$, so that $d p / \bar{q}_{s}^{F}(p)=\delta w / \beta^{2}$. Hence, $d p / d q_{s}^{I}(p)>d p / d \bar{q}_{s}^{F}(p)$. Let $\bar{l}_{d}^{F}(p)$ be the labour demand corresponding to $\bar{q}_{s}^{F}(p)$ : $\bar{l}_{d}^{F}(p)=\bar{q}_{s}^{F}(p) / \beta$. Solving $l_{d}^{I}(p)=\bar{l}_{d}^{F}(p)$ for $p \in\left(p^{F}\left(\lambda_{\min }\right), \bar{p}\left(\lambda_{\min }\right)\right]$, we find that $p=\bar{p}\left(\lambda_{\text {min }}\right)$. Therefore, in (b), $l_{d}^{I}(p)>\bar{l}_{d}^{F}(p)$, except at $p=\bar{p}\left(\lambda_{\text {min }}\right)$, where 
$l_{d}^{I}(p)=\bar{l}_{d}^{F}(p)$. Thus, $q_{s}^{I}\left(\bar{p}\left(\lambda_{\min }\right)<\bar{q}_{s}^{F}\left(\bar{p}\left(\lambda_{\min }\right)\right)\right.$, and $q_{s}^{I}\left(\bar{p}\left(\lambda_{\min }\right)=\bar{q}_{s}^{F}\left(\bar{p}\left(\lambda_{\min }\right)\right)\right.$ at some price $p=p_{x} \in\left(p^{F}\left(\lambda_{\min }\right), \bar{p}\left(\lambda_{\min }\right)\right]$.

(c) $p \in\left(\bar{p}\left(\lambda_{\min }\right), p^{*}\right]: q_{s}^{I}(p)=\left[\lambda^{I}(p)-\bar{\lambda}(p)\right] / 2 \delta=\left[c-\pi_{0}-2(\beta-1) p\right] / 2 \delta w$ and $q_{s}^{F}(p)=2 \beta\{\bar{\lambda}(p)-\Lambda+\delta\} / 2 \delta=\beta\{[(2 \beta-1) p-k-c] / w-\Lambda+\delta\} / \delta$; thus, $d p / d\left[q_{s}^{I}(p)+q_{s}^{F}(p)\right]=\delta w /\left(2 \beta^{2}-2 \beta+1\right)$. But, from $(\mathrm{b}), d p / \bar{q}_{s}^{F}(p)=\delta w / \beta^{2}$; so for $\beta>1, d p / \bar{q}_{s}^{F}(p)>d p / d\left[q_{s}^{I}(p)+q_{s}^{F}(p)\right] . q_{s}^{I}(p)+q_{s}^{F}(p)<\bar{q}_{s}^{F}(p)$, except at $p=p^{*}$, where $q_{s}^{I}(p)=0$ and so $q_{s}^{I}(p)+q_{s}^{F}(p)=\bar{q}_{s}^{F}(p)$. Q.E.D.

(d) and (e) $p \in\left(p^{*}, \infty\right): q_{s}^{I}(p)=0$ and $q_{s}^{F}(p)=\bar{q}_{s}^{F}(p)$; so $q_{s}^{I}(p)+q_{s}^{F}(p)=\bar{q}_{s}^{F}(p)$.

\section{Proposition 3}

Assume segmentation.

For $p \in\left(p^{*}, p^{I}\left(\lambda_{\max }\right)\right]$, from Corollary $1, q_{s}^{F}(p)+q_{s}^{I}(p)>\bar{q}_{s}^{F}(p)$. As labour productivity is lower with informality, $l_{s}^{F}(p)+l_{s}^{I}(p)>\bar{l}_{s}^{F}(p)$.

For $p \in\left(p^{I}\left(\lambda_{\max }\right), \bar{p}\left(\lambda_{\max }\right)\right], l_{s}^{F}(p)+l_{s}^{I}(p)=2 G[\bar{\lambda}(p)]+\left\{G\left[\lambda^{I}(p)\right]-G[\bar{\lambda}(p)]\right\}=$ $G[\bar{\lambda}(p)]+G\left[\lambda^{I}(p)\right]$, which is increasing in $p$. But for $\left.p \in\left[p^{F}\left(\lambda_{\max }\right)\right), \bar{p}\left(\lambda_{\max }\right)\right], \bar{l}_{s}^{F}(p)$ is constant. Since $l_{s}^{F}(p)+l_{s}^{I}(p)=\bar{l}_{s}^{F}(p)$ at $p=\bar{p}\left(\lambda_{\max }\right)$, for $\left.p \in\left[p^{F}\left(\lambda_{\max }\right)\right), \bar{p}\left(\lambda_{\max }\right)\right)$, $l_{s}^{F}(p)+l_{s}^{I}(p)<\bar{l}_{s}^{F}(p)$. For $p \in\left(p^{I}\left(\lambda_{\max }\right), p^{F}\left(\lambda_{\max }\right)\right], d\left(l_{s}^{F}(p)+l_{s}^{I}(p)\right) / d p=d\{G[\bar{\lambda}(p)]+$ $\left.G\left[\lambda^{I}(p)\right]\right\} / d p=[(2 \beta-1) /(w+2 s)+1 / w] 2 \delta$ and $d \bar{l}_{s}^{F}(p) / d p=d\{2 G[\bar{\lambda}(p)]\} / d p=$ $(2 \beta-1) /(w+2 s) \delta$. Therefore, $d \bar{l}_{s}^{F}(p) / d p-d\left(l_{s}^{F}(p)+l_{s}^{I}(p)\right) / d p=(s-\hat{s}) / \delta w(w+2 s)$ $>0$. So $\bar{l}_{s}^{F}(p)-\left[l_{s}^{F}(p)+l_{s}^{I}(p)\right]$ rises through this range, starting negative and ending positive. $\bar{l}_{s}^{F}(p)-\left[l_{s}^{F}(p)+l_{s}^{I}(p)\right]=0$ if $p=\tilde{p}^{l}$, where $\tilde{p}^{l}$ solves $G[\bar{\lambda}(p)]+G\left[\lambda^{I}(p)\right]=$ $2 G[\bar{\lambda}(p)]$, i.e., $\tilde{p}^{l}=[2(\pi+k) s+(\pi-c) w] / 2(s-\hat{s})$.

Assume no segmentation.

For $p \in\left(p^{I}\left(\lambda_{\min }\right), p^{F}\left(\lambda_{\min }\right)\right], l_{d}^{I}(p)>0=l_{d}^{F}(p)$.

For $p \in\left[p^{F}\left(\lambda_{\min }\right), \bar{p}\left(\lambda_{\min }\right)\right]$, from the proof of Corollary $2, l_{d}^{I}(p)>\bar{l}_{d}^{F}(p)$, except at $p=\bar{p}\left(\lambda_{\min }\right)$, where $l_{d}^{I}(p)=\bar{l}_{d}^{F}(p)$.

For $p \in\left(\bar{p}\left(\lambda_{\min }\right), p^{*}\right], l_{d}^{I}(p)=\left[\lambda^{I}(p)-\bar{\lambda}(p)\right] / 2 \delta=\left[c-\pi_{0}-2(\beta-1) p\right] / 2 \delta w$ and $l_{d}^{F}(p)=2\{\bar{\lambda}(p)-\Lambda+\delta\} / 2 \delta=\{[(2 \beta-1) p-k-c] / w-\Lambda+\delta\} / \delta$; thus, $d p / d\left[l_{d}^{I}(p)+l_{d}^{F}(p)\right]=\delta w / \beta$. But $\bar{l}_{d}^{F}(p)=2 G\left[\lambda^{F}(p)\right]=\left[\lambda^{F}(p)-\Lambda+\delta\right] / \delta=$ $\left\{\left(2 \beta p-2 k-c-\pi_{0}\right) / 2 w-\Lambda+\delta\right\} / \delta$, so that $d p / d \bar{l}_{d}^{F}(p)=\delta w / \beta=d p / d\left[l_{d}^{I}(p)+l_{d}^{F}(p)\right]$. Thus, since $l_{d}^{I}\left(\bar{p}\left(\lambda_{\min }\right)\right)+l_{d}^{F}\left(\bar{p}\left(\lambda_{\min }\right)\right)=\bar{l}_{d}^{F}\left(\bar{p}\left(\lambda_{\min }\right)\right), l_{d}^{I}(p)+l_{d}^{F}(p)=\bar{l}_{d}^{F}(p)$ for all of this $p$-range. Q.E.D.

\section{References}

AHSAN, A., AND C. PAGES [2007], Are all Labor Regulations Equal? Assessing the Effects of Job Security, Labor Dispute, and Contract Labor Laws in India, World Bank Policy Research Working Paper No. 4259. 
ALBRECHT, J., L. NAVARRO AND S. VROMAN [2009], "The Effects of Labour Market Policies in an Economy with an Informal Sector," Economic Journal, 119, 1105-1129.

AMARAL, P. S., AND E. QUINTIN [2006], "A Competitive Model of the Informal Sector," Journal of Monetary Economics, 53, 1541-53.

ANTUnES, A. R., AND T. V. DE V. CAVALCANTI [2007], "Start Up Costs, Limited Enforcement, and the Hidden Economy," European Economic Review, 51, 202-224.

BADAOUI, E., E. STROBL AND F. WALSH [2008], "Is There an Informal Employment Wage Penalty? Evidence from South Africa," Economic Development and Cultural Change, 56, 683-710.

BANERJI, A., AND S. JAIN [2007], "Quality Dualism," Journal of Development Economics, 84, 234-250.

BENNETT, J. [2010], "Informal Firms in Developing Economies: Entrepreneurial Stepping Stone or Consolation Prize?" Small Business Economics, 34, 53-63.

BOSCH, M. [2007], Job Creation and Job Destruction in the Presence of Informal Labour Markets, London School of Economics, mimeo.

BOSCH, M., AND W. MALONEY [2008], Cyclical Movements in Unemployment and Informality in Developing Countries, IZA Discussion Paper No. 3514.

BOURGUIGNON, F. [2005], Development Strategies for More and Better Jobs, paper presented at the conference 'Help Wanted: More and Better Jobs in a Globalized Economy,' Washington DC, http://siteresources.worldbank.org/DEC/Resources/847971104785060319/bourguignondevelopmentstrategiesformoreandbetterjobs.PDF

COLliER, P., AND J. W. GUNNING [1999], "Explaining African Growth Performance," Journal of Economic Literature, 37, 64-111.

DE PAULA, A., AND J. SCHEINKMAN [2008], The Informal Sector, PIER Working Paper 08-018, University of Pennsylvania.

DJANKOV, S., R. LA PORTA, F. LOPEZ-DE-SILANES, AND A. SHLEIFER (2002), "The Regulation of Entry," Quarterly Journal of Economics, 117, 1-35.

FIELDS, G. [2009], "Segmented Labor Market Models in Developing Countries," in H. Kincaid and D. Ross (eds.) The Oxford Handbook of the Philosophy of Economic Science, Oxford University Press: Oxford and New York. 
FORTIN, B., N. MARCEAU AND L. SAVARD [1997], "Taxation, Wage Controls and the Informal Sector," Journal of Public Economics, 66, 293-312.

GOLDBERG, N., AND P. PAVCNIK [2003], "The Response of the Informal Sector to Trade Liberalization, Journal of Development Economics, 72, 463-496.

IHRIG, J., AND K. S. MOE [2004], "Lurking in the Shadows: the Informal Sector and Government policy," Journal of Development Economics, 73, 541-557.

JOVANOVIC, B. [1982], "Selection and the Evolution of Industry," Econometrica, 50, 649-670.

LA FERRARA, E. [2003], "Kin Groups and Reciprocity: a Model of Credit Transactions in Ghana," American Economic Review, 93, 1730-1751.

LEWIS, W. A. [1954], "Economic Development with Unlimited Supplies of Labour," Manchester School, 28, 139-191.

LUCAS, R. E. [1978], "On the Size Distribution of Business Firms," Bell Journal of Economics, 9, 508-523.

MALONEY, W. [2004], "Informality Revisited," World Development, 32, 11591178.

PARKER, S. C. [2004], The Economics of Self-Employment and Entrepreneurship, Cambridge University Press: Cambridge, UK.

RAUCH, J. E. [1991], "Modelling the Informal Sector Formally," Journal of Development Economics, 35, 33-47.

SCHNEIDER, F. [2006], "Shadow Economies of 145 Countries all over the World: What do we Really Know?" Working Paper, Johannes Kepler University of Linz.

SCHNEIDER, F., AND D. ENSTE [2000], "Shadow Economies: Size, Causes, and Consequences, Journal of Economic Literature, 38, 77-114.

STRAUB, S. [2005], "Informal Sector: the Credit Market Channel," Journal of Development Economics, 78, 299-321.

TEAL, F. [1996], "The Size and Sources of Economic Rents in a Developing Country Manufacturing Labour Market," Economic Journal, 106, 963-976.

ULYSSEA, G. [2010], "Regulation of entry, labor market institutions and the informal sector," Journal of Development Economics, 91, 87-99. 
WALTHER, R. AND E. FILIPIAK [2007], Vocational Training in the Informal Sector, Research Report, Research Department, Agence Française de Développement, Paris.

WORLD BANK [2007], Informality: Exit and Exclusion, World Bank: Washington D.C.

Brunel University, Uxbridge, Middlesex, UB8 3PH, United Kingdom. 